\title{
Duloxetine Attenuates Paclitaxel-Induced Peripheral Nerve Injury by Inhibiting p53-Related Pathways ${ }^{\text {[ }}$
}

\author{
Yuting Lu, ${ }^{1}$ Peng Zhang, ${ }^{1}$ Qiuyan Zhang, Chao Yang, Yangyan Qian, Jinshuai Suo, \\ Xinxia Tao, and Jing Zhu
}

Jiangsu Key Laboratory for Pharmacology and Safety Evaluation of Chinese Materia Medica, Department of Pharmacy, Nanjing University of Chinese Medicine, Nanjing, China (Y.L., P.Z., Q.Z., C.Y., Y.Q., J.S., X.T., J.Z.); Departments of Neurology and Neuroscience, Johns Hopkins University School of Medicine, Baltimore, Maryland (J.Z.)

Received January 9, 2020; accepted March 18, 2020

\section{ABSTRACT}

Paclitaxel (PTX) is an antineoplastic drug extracted from the Taxus species, and peripheral neuropathy is a common side effect. Paclitaxel-induced peripheral neuropathy (PIPN) seriously affects patient quality of life. Currently, the mechanism of PIPN is still unknown, and few treatments are recognized clinically. Duloxetine is recommended as the only potential treatment of chemotherapy-induced peripheral neuropathy (CIPN) by the American Society of Clinical Oncology. However, this guidance lacks a theoretical basis and experimental evidence. Our study suggested that duloxetine could improve PIPN and provide neuroprotection. We explored the potential mechanisms of duloxetine on PIPN. As a result, duloxetine acts by inhibiting poly ADP-ribose polymerase cleavage (PARP) and tumor suppressor gene p53 activation and regulating apoptosis regulator the $\mathrm{Bcl} 2$ family to reverse PTX- induced oxidative stress and apoptosis. Taken together, the present study shows that using duloxetine to attenuate PTXinduced peripheral nerve injury and peripheral pain may provide new clinical therapeutic targets for CIPN.

\section{SIGNIFICANCE STATEMENT}

This study reported that duloxetine significantly alleviates neuropathic pain induced by paclitaxel and is related to poly ADP-ribose polymerase (PARP), tumor suppressor gene p53, and apoptosis regulator the Bcl2 family. Our findings thus not only provide important guidance to support duloxetine to become the first standard chemotherapy-induced peripheral neuropathy (CIPN) drug but also will find potential new targets and positive control for new CIPN drug development.

\section{Introduction}

Chemotherapy-induced peripheral neuropathy (CIPN) is an oft-reported dose-limiting side effect of neurotoxic chemotherapeutic agents [for example, paclitaxel (PTX), oxaliplatin, and vincristine] (Cata et al., 2006). PTX stabilizes microtubules and is commonly used in the treatment of breast, ovarian, and cervical cancer (Hagiwara and Sunada, 2004). However, patients treated with PTX often suffer from paresthesia, allodynia (pain caused by stimulus that produces no pain in general), and hyperalgesia (increased pain from stimulus that causes pain in general), such as tingling or numbness in the hands or feet, pain provoked by normal behaviors of daily life, etc.; this paclitaxel-induced peripheral neuropathy (PIPN) is

This study was supported by Key Project of Jiangsu Province for Fundamental Research and Development (BE2018717); the dual creative team of Jiangsu Province (2018-2020); specially-appointed Professor Grant by JiangSu province (2014, Prof. J.Z.); Jiangsu Six Talent Peak Award (2015, Prof. J.Z.); and Postgraduate Research and Practice Innovation Program of Jiangsu Province.

${ }^{1}$ Y.L. and P.Z. contributed equally to this work

https://doi.org/10.1124/jpet.120.265082.

S This article has supplemental material available at jpet.aspetjournals.org. a serious problem for most patients and reduces quality of life (Dougherty et al., 2004; Jensen and Finnerup, 2014). Unfortunately, there are few effective medications for this peripheral neuropathic pain (Wolf et al., 2008; Gihyun and Sun, 2016; Brandolini et al., 2019). Therefore, most of the drugs currently used to modulate neuropathic pain are painkillers, including opioids, cannabinoid receptor modulators, and sodium channel blockers (Jensen and Finnerup, 2014).

Apoptosis is a process of polygene regulation. Many proteins are involved in PTX-induced apoptosis, such as p53 and poly ADP-ribose polymerase (PARP), caspase- 3 , caspase-9, and the Bcl2 family (McNeish et al., 2004; Yin et al., 2012; Xu et al., 2015). The tumor suppressor gene $\mathrm{p} 53$, a major transcriptional regulator, is upregulated after cellular stress signaling, including DNA damage, hypoxia, and chemotherapy. The accumulation of p53 regulates many cellular processes, including apoptosis and autophagy. Cisplatin inhibits activity of phosphatidylinositol 4,5-bisphosphate 3-kinase catalytic subunit alpha isoform (PIK3CA) promoter and weakens survival pathways of phosphatidylinositol 3 kinase(PI3K) /protein kinase $\mathrm{B}(\mathrm{AKT})$ cells through activating p53 in sensitive cells

ABBREVIATIONS: BAX, Bax apoptosis regulator; BCL2, Bcl2 apoptosis regulator; CCK-8, Cell Counting Kit-8; CIPN, chemotherapy-induced peripheral neuropathy; DAPI, 4',6-diamidino-2-phenylindole; DRG, dorsal root ganglia; GAPDH, glyceraldehyde-3-phosphate dehydrogenase; PA1, human ovarian teratoma cells; p53, tumor suppressor gene; PARP, poly ADP-ribose polymerase; PCR, Polymerase Chain Reaction; pft- $\alpha$, pifithrin- $\alpha$; PIPN, paclitaxel-induced peripheral neuropathy; PTX, paclitaxel; qPCR, quantitative Polymerase Chain Reaction; siRNA, small interfer RNA; TBST, Tris-buffered saline/Tween-20. 
(Thakur and Ray, 2016). Furthermore, studies have shown that PTX remarkably upregulated the expression of PARP1, apoptosis regulator Bax, and some of the caspase family, such as caspase-3 and caspase-9, and downregulated the expression of Bcl2 in K562 cancer cells, which indicates that PTX regulates the intrinsic apoptotic signaling pathway to induce cell apoptosis (Wang et al., 2017). p53 and its downstream pathways play a key role in preventing tumor formation (Neitemeier et al., 2014). p53 dysfunction leads to neuronal damage, and p53 can mediate cell death by inducing Bax (Bcl2 family proteins) and the BH3-interacting domain death agonist (Bid), Bcl-2-binding component 3 (PUMA), and phorbol-12-myristate-13-acetate-induced protein 1 (NOXA) (Culmsee and Mattson, 2005; Culmsee and Landshamer, 2006; Vousden and Prives, 2009). Moreover, knockout or inhibition of p53 has a beneficial effect on nerve damage (Xiang et al., 1996; Culmsee et al., 2003; Plesnila et al., 2007). PARP1 is a protease with multiple physiologic functions involved in DNA damage repair. Research has shown that oxidative stress produced by chemotherapy or high glucose-induced nerve damage causes excessive activation of PARP1, and ATP and $\mathrm{NAD}^{+}$are depleted in cells, which ultimately leads to cell apoptosis (Haince et al., 2005; Langelier et al., 2008; Kuzhandaivel et al., 2010; Wang et al., 2016).

At present, the main treatments for PIPN have many side effects; the mechanisms of action of these drugs are still unclear, and clinical application has not been recognized. Duloxtine, an antidepressant drug that inhibits serotonin and norepinephrine uptake, has been approved by the US Food and Drug Administration (FDA) for a wide range of chronic neuropathic pain, including diabetic peripheral neuropathic pain and fibromyalgia (Yang et al., 2012; Miyazaki and Yamamoto, 2012; Takenaka et al., 2013; Finnerup et al., 2015). Duloxtine was also recommended by the American Society of Clinical Oncology as the only clinical drug for the treatment of CIPN. However, studies of duloxetine have mainly focused on clinical applications. Early case reports and small-scale open clinical studies suggest that duloxetine is effective for CIPN, but relevant research is still limited, and there is no basis for the theoretical system. There are fundamental problems that have not yet been answered. The mechanism of action of duloxtine when used to treat CIPN is an important issue.

Therefore, we aimed to clarify the effects of duloxetine on PTX-induced peripheral neuropathic pain in vivo and in vitro and to determine whether the p53 apoptotic signaling pathway induced by PTX is associated with the preventive impact of duloxetine on PIPN.

\section{Materials and Methods}

\section{In Vitro Studies}

Drugs. PTX (Sigma) was dissolved in DMSO (Solarbio, China) to a concentration of $300 \mu \mathrm{M}$. Duloxetine (Shanghai Yuanye, China) was dissolved in DMSO to a concentration of $10 \mathrm{mM}$. All drugs were then diluted in the appropriate medium to a specified working standard concentration. Pifithrin- $\alpha$ (pft- $\alpha$, p53 inhibitor; Nanjing Jiancheng Bioengineering Institute, China) was dissolved in DMSO to a concentration of $74 \mathrm{mM}$.

Cell Culture and Drug Treatments. Dorsal root ganglia (DRGs) were dissected from Sprague-Dawley rats within 1-3 days of birth and immediately incubated with collagenase I solution $(3 \mathrm{mg} / \mathrm{ml}$;
Worthington Biochemical Corporation, United Kingdom) at $37^{\circ} \mathrm{C}$ for 50 minutes. The suspension was centrifuged at $1500 \mathrm{rpm}$ for 2 minutes and then resuspended, and the cells were seeded in plates at a density of $10^{5}$ cells $/ \mathrm{ml}$ in Neurobasal medium (Gibco) added in $1 \%$ penicillin/ streptomycin (Gibco), 10\% FBS (Gibco), $0.5 \mathrm{mM}$ glutamine, $1 \times$ B-27 supplement (Gibco), $0.2 \%$ glucose, and $10 \mu \mathrm{g} / \mathrm{ml}$ human glial-derived neurotrophic factor (Peprotech) in a $37^{\circ} \mathrm{C}, 5 \% \mathrm{CO}_{2}$ incubator for 24 hours. All culture plates were previously coated with poly-L-lysine ( $3 \mu \mathrm{g} / \mathrm{ml}$; Sigma). Then, the cells were exposed to culture medium containing $2 \%$ FBS with PTX $(300 \mathrm{nM})$ for the model group and duloxetine (300 nM) for the treatment group (Meng et al., 2019). The untreated cells were cultured in complete medium without any drugs.

Cell Viability. Cell viability was detected by Cell Counting Kit-8 (CCK-8) assay (Yeasen, China), which is based on the ability of cells to convert WST-8 (2-(2-methoxy-4-nitrophenyl)-3-(4-nitrophenyl)-5-(2,4disulfophenyl)-2H-tetrazolium,monosodium salt substrate into yellow formazan. Briefly, after treatment with PTX (300 nM) and/or varying concentrations of pft- $\alpha$ for 24 hours, CCK- 8 solution at $10 \mu$ l per well was added to cells in 96 -well plates and incubated for 4 hours at $37^{\circ} \mathrm{C}$. Then, the color intensity reflecting cell growth was examined at 450 $\mathrm{nm}$ using a multimode plate reader (Tecan, Switzerland).

Cell Apoptosis. Cell apoptosis was analyzed by flow cytometric analysis. Briefly, after drug treatment, the cells were washed and collected according to the directions of the Annexin V-FITC/PI Apoptosis Detection Kit (KeyGen, China). The cells were resuspended in $500 \mu \mathrm{l}$ of binding buffer, and $5 \mu \mathrm{l}$ of Annexin V-FITC and propidium iodide were added and incubated for 15 minutes in the dark. The proportion of apoptotic cells was determined and analyzed by flow cytometry (Accuri C6; BD).

Antitumour Activity. The cancer cell line PA-1 (human ovarian teratoma cells) was cultured to assess the effects of duloxetine and pft$\alpha$ on PTX-induced cell death using the CCK- 8 assay. PA- 1 cells were incubated in high-glucose DMEM (HyClone) containing 10\% FBS (Gibco) and 1\% penicillin-streptomycin. After PTX treatment (300 nM) and different concentrations of duloxetine and pft- $\alpha$, CCK- 8 solution $(10 \mu \mathrm{l})$ was added to each well. After 4 hours, absorbance was measured at $450 \mathrm{~nm}$.

\section{In Vivo Studies}

Animals. All procedures involving animals were conducted in accordance with the ethical guidelines established by the International Association for the Study of Pain (Eum et al., 2013), and the protocols were approved by the Animal Committee of Nanjing University of Chinese Medicine (approval number ACU171001). In the study, we used C57BL/6 mice (18-22 g; Nanjing QingLongShan, China). Food and water were freely available. The animals were housed in a room with a normal 12-hour light/dark cycle. All animals were habituated in the room for 1 week before experiments; all experiments were evaluated in a blinded manner.

Drugs. Paclitaxel (Shanghai Jinhe, China) was dissolved with Cremophor EL and ethanol at a ratio of $1: 1$ and a concentration of $6 \mathrm{mg} / \mathrm{ml}$ and then diluted to $2 \mathrm{mg} / \mathrm{ml}$ with $0.9 \%$ sterile saline. Duloxetine (Shanghai Yuanye) was dissolved in $0.9 \%$ sterile saline at a concentration of $3 \mathrm{mg} / \mathrm{ml}$ and then diluted to $2 \mathrm{mg} / \mathrm{ml}$ and $1 \mathrm{mg} / \mathrm{ml}$.

PTX -Induced Neuropathic Pain Model. The mice were randomly divided into the following six groups, with 10 mice per group: the control group (control); the paclitaxel model group (PTX); the duloxetine-treatment group with high $(\mathrm{H})$, medium $(\mathrm{M})$, and low $(\mathrm{L})$ concentrations of duloxetine $[\mathrm{P}+\mathrm{D}(\mathrm{H}), \mathrm{P}+\mathrm{D}(\mathrm{M})$, and $\mathrm{P}+\mathrm{D}(\mathrm{L})]$; and the duloxetine-alone treatment group (D). The mice were treated with PTX intraperitoneally at a dose of $20 \mathrm{mg} / \mathrm{kg}$ every other day (days 1,3 , 5 , and 7; cumulative dose, $80 \mathrm{mg} / \mathrm{kg}$ ) to model PTX-induced peripheral pain (Melli et al., 2006; Krukowski et al., 2015). Control mice were injected with vehicle only. There were three duloxetine treatment groups with different doses of duloxetine: $10[\mathrm{P}+\mathrm{D}(\mathrm{L})], 20[\mathrm{P}+\mathrm{D}(\mathrm{M})]$, and $30 \mathrm{mg} / \mathrm{kg}[\mathrm{P}+\mathrm{D}(\mathrm{H})]$ (Shidahara et al., 2016; Toyama et al., 2017). Duloxetine was injected intraperitoneally daily; in the treatment 
groups, duloxetine was administered 1 hour before an injection of PTX.

\section{Detection of Intracellular Oxidative Stress}

MitoTracker Red CM- $\mathrm{H}_{2}$ XRos (Yeasen) was employed to detect the levels of intracellular oxidative stress. When the treatment was completed, cells were washed three times with PBS and then loaded with MitoTracker Red CM- $\mathrm{H}_{2}$ XRos $(500 \mathrm{~nm})$ in fresh Neurobasal medium for 45 minutes at $37^{\circ} \mathrm{C}$. After dyeing, the cells were washed three times with PBS and fixed with prewarmed $4 \%$ paraformaldehyde solution for 20 minutes. After washing with PBS, the cells were stained with Hoechst for 20 minutes. The fluorescence was then quantified, and the images were collected using fluorescence microscopy (IX71; Olympus, Japan).

\section{Behavior Studies}

Behavior was evaluated after drug injection weekly (days $0,7,14$, 21 , and 28) and conducted at room temperature. The body weights of the mice were recorded weekly. The investigator was blinded to the treatment groups $(n=10)$.

Measurement of Mechanical Hyperalgesia. To measure mechanical hyperalgesia, we used the Dynamic Plantar Aesthesiometer (Ugo Basile, Italy). The mice were placed in a plastic chamber to acclimate for half an hour prior to the test. Force was transferred to the hind paw at a frequency of $1 \mathrm{~g} / \mathrm{s}$. To minimize damage, the cutoff force was set at $10 \mathrm{~g}$. The nociceptive threshold was determined when paw withdrawal occurred, which was assessed on each hind paw for three trials in total per mouse.

Measurement of Thermal Nociception. The thermal withdrawal thresholds were assessed using a plantar test (37370; Ugo Basile Plantar Test Apparatus). Mice were allowed to acclimate to the glass floor for 30 minutes before the test. An infrared source was located at the center of the hind paw of the mice, and heat could transfer rapidly. The time of withdrawal was recorded when the heat source was switched off. To avoid injury, a cutoff period of 20 seconds was maintained. The thermal withdrawal threshold was determined by the average of three treatments per mouse.

Measurement of Cold Allodynia. The mouse was placed in a fixing apparatus with only the tail exposed. The tail of the mouse was immersed in a water bath maintained at $4^{\circ} \mathrm{C}$ until tail withdrawal. To avoid damage to the tail, the cutoff time was set at 20 seconds. The behavior test was repeated three times for each mouse, with a time interval of at least 15 minutes between two measurements.

\section{Western Blot Analysis}

On the last day at the end of week 4, the DRGs were removed from the mice for Western blot analysis. The DRGs were homogenized in Radio-Immunoprecipitation Assay (RIPA) buffer and Phenylmethanesulfonyl fluoride (PMSF) (a protease inhibitor) at a ratio of 100:1. Then, homogenates were centrifuged at 12,000g for 15 minutes at $4^{\circ} \mathrm{C}$. Using a BCA protein assay kit, the protein supernatants were collected and measured. Proteins $(20 \mu \mathrm{g})$ were separated by $10 \%$ SDS polyacrylamide gels and transferred onto Polyvinylidene Fluoride (PVDF) membranes in transfer buffer for 60 minutes. The membranes were soaked in Tris-buffered saline/Tween-20 (TBST) containing $5 \%$ nonfat milk for 60 minutes at room temperature and incubated with rabbit polyclonal antibodies against Bax (1:2000; Abcam, MA), Bcl2 (1:2000; Abcam), and PARP1 (1:2000; Abcam) and mouse monoclonal antibodies against $\beta$-actin (1:8000; Cell Signaling Technology) and p53 (1:2000; Cell Signaling Technology) overnight at $4^{\circ} \mathrm{C}$. The membranes were then washed in TBST three times and incubated with horseradish peroxidase-conjugated goat anti-rabbit IgG (1:10,000; Cell Signaling Technology) or horseradish peroxidaseconjugated goat anti-mouse IgG (1:10,000; Cell Signaling Technology) for 60 minutes at room temperature. The membranes were washed in TBST three times again, and the bands were detected by enhanced chemiluminescence. The gray values were quantified using ImageJ software.

\section{Immunohistochemistry}

On the last day at the end of week 4, the L4 and L5 DRGs were removed from mice for immunohistochemical analysis. The DRGs were fixed in $4 \%$ paraformaldehyde overnight and dehydrated with $30 \%$ sucrose solution. The DRGs were cut in $10-\mu \mathrm{m}$ thickness and mounted on glass slides. After treating with $0.5 \%$ Triton X-100 in PBS for 20 minutes and washing with PBS three times quickly, the sections were blocked in 5\% normal goat serum and 0.5\% Tween-20 in PBS for 1 hour at room temperature. The sections were washed with PBS three times again and incubated in primary antibodies containing p53 (1: 1000; Cell Signaling Technology) overnight at $4^{\circ} \mathrm{C}$. After washing with PBS three times, the sections were incubated in fluorescein isothiocyanate (FITC)-conjugated secondary antibodies (1:100) for 1 hour in the dark at room temperature. Then, the sections were washed three times and stained with DAPI. The immunostained DRGs were viewed under an inverted fluorescence microscope.

\section{Quantitative Real-Time Polymerase Chain Reaction}

Total RNA was extracted from DRGs using TRIzol (Invitrogen, Carlsbad, CA). RNA was used to synthesize cDNA with ReverTra Ace qPCR RT Master Mix with genomic DNA (gDNA) Remover (Toyobo Co., Ltd. Life Science Department, Japan). Real-time PCR was conducted with an Applied Biosystems 7500 Real-Time PCR System (Life Technologies) using TransStart Top Green qPCR SuperMix (TransGen Biotech, Beijing, China). GAPDH was used as an internal reference, and primers were synthesized by Shanghai Sangon Biotech. The primer sequences were as follows: GAPDH, (forward) 5 '-GGT TGT CTC CTG CGA CTT CA-3', (reverse) 5' -TGG TCC AGG GTT TCT TAC TCC-3'; p53, (forward) 5'-CGC CGA CCT ATC CTT ACC AT-3', (reverse) $5^{\prime}$-TCT TCT GTA CGG TCT CTC-3'; and PARP1, (forward) 5'-CAG TGC CAG TCA GCT CAA GG-3'; (reverse) $5^{\prime}$-TGT TCC ATC CAC CTC GTC AC- $3^{\prime}$. In all cases, the effectiveness of amplification was determined by the presence of a single peak in the melting temperature analysis and linear amplification throughout the PCR cycles. The $2^{-\Delta \Delta \mathrm{Ct}}$ relative quantification method was used to calculate the relative mRNA impression of the target genes.

\section{RNA Interference}

The transfection of p53 small interfer RNA (siRNA) into DRG cells was performed according to standard protocols. Cells were cultured in plates with Neurobasal medium for 24 hours. The next day, the cells were incubated with $20 \mu \mathrm{M}$ p53 siRNA and transfection reagent in serum-free Neurobasal medium for 4-6 hours, and then Neurobasal medium containing $2 \%$ FBS was added to each well for 24 hours. Then, the cells were cultured with PTX and/or duloxetine. Furthermore, the cells were also transfected with a fluorescein-labeled control siRNA to detect the transfection efficiency.

\section{Statistical Analysis}

All experimental data were analyzed using GraphPad Prism 5. The differences between groups were analyzed by two-way ANOVA followed by Bonferroni post-tests. $P<0.05$ was considered significant.

\section{Results}

Duloxetine Prevented PTX-Induced Pain Hypersensitivity in the Mice. The mice were injected with duloxetine daily, and pain behavior was assessed on the first day of every week. At baseline, there was no significant difference in status between the six groups of mice. Pain behavior tests showed that, compared with the vehicle-controlled mice, 
the PTX-treatment group showed significant decreases in the paw withdrawal latency from the 2 nd week to the 4 th week in the mechanical hyperalgesia test and from the 1st week to the 4th week in the thermal nociception test (Fig. 1, A and B). In the PTX-treated group, the paw withdrawal threshold rapidly decreased from $6.02 \pm 0.65 \mathrm{~g}$ before PTX to $4.25 \pm 0.69 \mathrm{~g}$ at week $2(P<0.001$ vs. vehicle control, $n=8-10$ in each group $)$ and persisted until week 4 in the mechanical hyperalgesia test. Similarly, in the model group, the paw withdrawal latency time was significantly decreased from $14.60 \pm 1.28$ seconds to $12.75 \pm 1.04$ seconds at week $1(P<0.001$ vs. vehicle control, $n=8-10$ ) and to $8.80 \pm 1.66$ seconds at week 4 in thermal nociception tests. On the other hand, the paw withdrawal threshold was increased in the mice treated with duloxetine before PTX compared with the PTX-treated group for mechanical hypersensitivity (Fig. 1A), and the mice pretreated with duloxetine, whether at the high, middle, or low dose, all had higher reaction latency times compared with the model group for heat sensitivity (Fig. 1B). In contrast, the mice treated with PTX, with or without duloxetine, showed no difference in the tail withdrawal latency times compared with the vehicle-treated group in the cold allodynia test (Fig. 1C), which indicated that PTX did not cause cold hypersensitivity in the mice.

Duloxetine Did Not Change PTX-Induced Body Weight. To examine whether duloxetine affected body weight in the model of PTX-induced peripheral pain, body weight was assessed in mice with or without duloxetine after PTX treatment. The assessment revealed that, compared with the vehicle control mice, there was no significant effect on body weight after PTX treatment, and the administration of duloxetine did not induce any alteration or enhancement on the physiologic body weight compared with the model group (Fig. 1D). Body weights were measured weekly starting from the first injection of duloxetine through the end of the experiment.

Duloxetine Had No Effect on the Antitumour Activity of PA-1 Cells to PTX. Then, we measured PA-1 cell viability to evaluate the impact of duloxetine on the antitumour activity of PTX. The cells were exposed to different concentrations of PTX and cotreated with different doses of duloxetine with the best concentration of PTX. As shown in Fig. 2A, each concentration of PTX had a strong ability to kill cancer cells. At or above $1 \mathrm{nM}$ concentration, PTX caused more than $50 \%$ of PA- 1 cells death; cell viability was only $30 \%$ at $300 \mathrm{nM}$, and cotreatment with different concentrations of duloxetine with $300 \mathrm{nM}$ PTX did not decrease the ability of PTX to kill PA-1 cells (Fig. 2B).

Duloxetine Suppressed PTX-Induced Oxidative Stress in DRG Neurons. MitoTracker Red CM-H2XRos, a reduced red fluorescent dye, does not fluoresce itself but is oxidized to fluoresce when it enters cells; thereby, it can be used to detect oxidative stress levels in DRG cells. Hoechst is a nuclear marker that stains the nucleus blue. Compared with the control group, the fluorescence intensity of CM-H2XRos was significantly enhanced after PTX treatment, and the fluorescence intensity was weakened after the intervention of duloxetine, as shown in Fig. 2C. Quantitative histograms showed a significant difference between the model group and the control group, and there was a significant difference between the duloxetine-administered group and the model group. The fluorescence intensity of the duloxetine-alone group was not significantly different from that of the blank control group. It can be noted that PTX causes oxidative stress in DRG cells, leading to peripheral nerve injury, and duloxetine
A

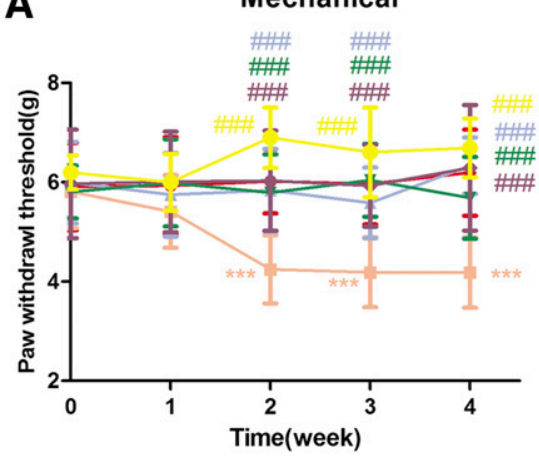

C

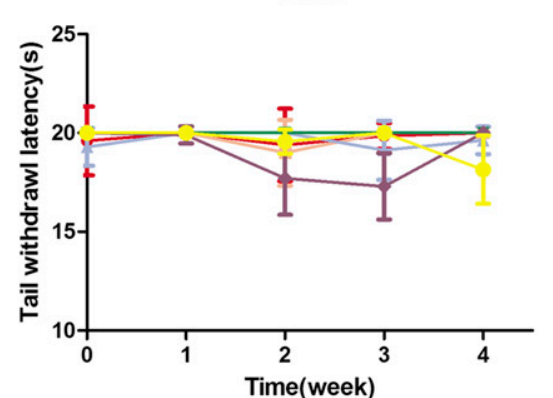

B

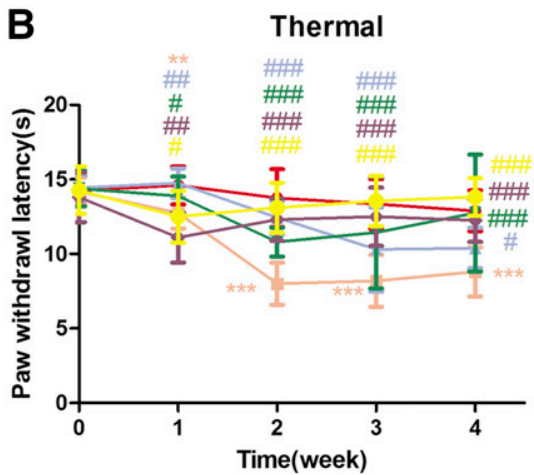

D

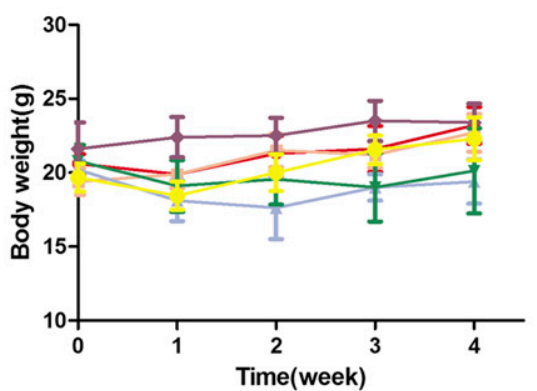

Fig. 1. Duloxetine alleviates PTX-induced hypersensitivity in C57BL/6 mice without affecting their body weight. (A) Paw withdrawal threshold was significantly decreased at week 2 and maintained for more than 3 weeks in mice treated with PTX. Duloxetine at doses of 10, 20, and $30 \mathrm{mg} / \mathrm{kg}$ all attenuated PTX-induced mechanical hyperalgesia. (B) Paw withdrawal threshold was significantly decreased at week 1 and maintained for more than 4 weeks in mice treated with PTX. Duloxetine at doses of 10, 20, and $30 \mathrm{mg} / \mathrm{kg}$ all attenuated PTX-induced thermal nociception. (C) PTX did not have a significant effect on cold tail withdrawal latency. Similarly, no effect was observed with duloxetine on mice treated with or without PTX. (D) The effect of duloxetine on body weight in mice treated with or without PTX. No significant difference between the model group and the duloxetine-treated group in mice $(* * P<0.01$; ${ }_{* * *} P<0.001$ vs. control; ${ }^{\#} P<0.05 ;{ }^{\# \#} P<0.01$;

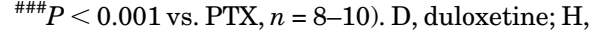
high; L, low; M, medium; P, paclitaxel. 
A

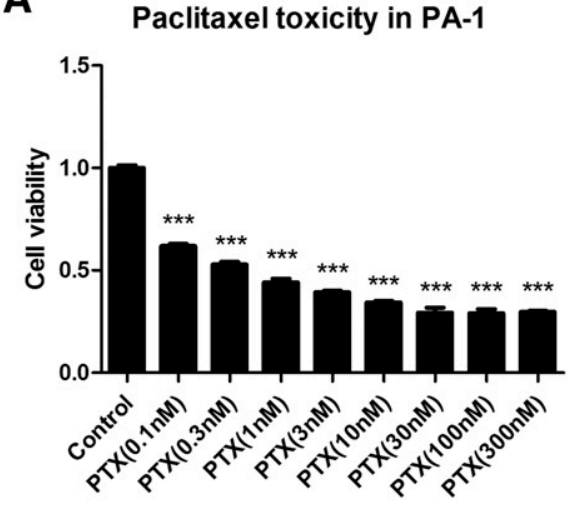

B

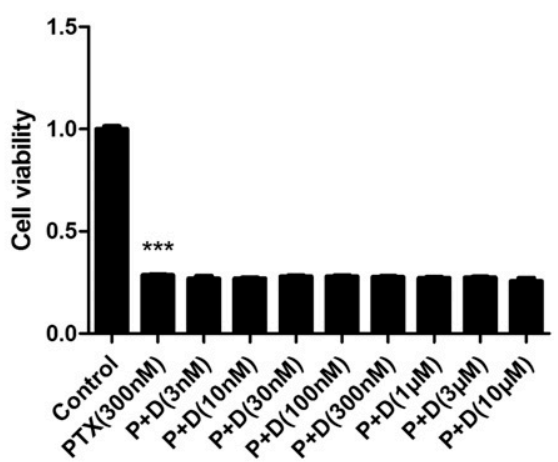

C

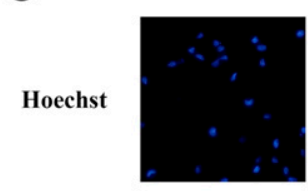

CM-H2Ros

Merge

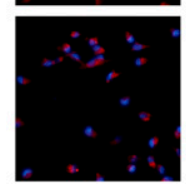

PTX

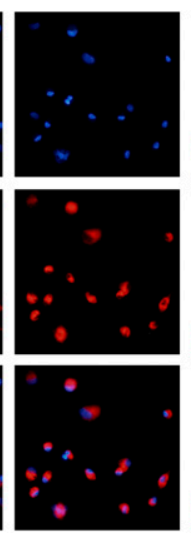

P+D

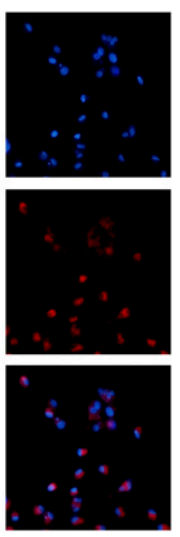

D

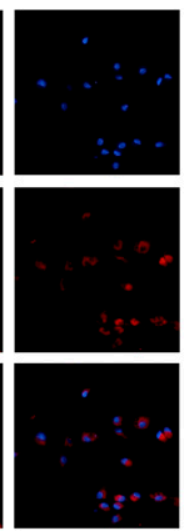

Fig. 2. Duloxetine has no effect on the antitumour activity of PTX in DRG neurons, but it can alleviate the oxidative stress induced by PTX. (A) When PA-1 cancer cells were grown for 24 hours, PTX showed toxicity and reduced their cell viability by $40 \%-80 \%$. (B) Various concentrations of duloxetine $(10 \mu \mathrm{M}-300 \mathrm{nM})$ together with PTX (300 nM) showed no significant changes in cell viability compared with treatment with PTX alone. (C) Primary rat DRG neurons were grown for 24 hours and then treated with PTX $(300 \mathrm{nM})$ and/or duloxetine for another 24 hours. Cells were then subjected to MitoTracker Red CM-H2XRos staining. The fluorescence intensity was observed using fluorescence microscopy (original magnification, $200 \times)(* * *$ vs. control, $P<0.001$; \#\#\# vs. PTX, $P<0.001, \alpha=0.05, n=6$ ). P, paclitaxel; D, duloxetine. can significantly reduce the level of oxidative stress induced by PTX.

Duloxetine Alleviated PTX-Induced p53 and PARP1 Levels. To investigate the effects of cell apoptotic signaling pathway in PIPN, we examined protein levels in DRG tissues and the sciatic nerve. Western blotting suggested that the expression of p53 and cleaved PARP1 was increased after PTX treatment in DRG tissues (Fig. 3A) and the sciatic nerve (Fig. 3B). In addition, at a dose of 30,20 , or $10 \mathrm{mg} / \mathrm{kg}$, duloxetine decreased PTX-induced p53 and cleaved PARP1 expression in DRG tissues (Fig. 3A) and the sciatic nerve (Fig. 3B). The changes of expression were similar to that in primary rat DRG neurons (Supplemental Fig. 1). We next investigated p53 expression in the DRG in vivo and in vitro using immunostaining (Fig. 4C; Supplemental Fig. 2). The results showed that duloxetine attenuated PTX-induced immunoreactivity compared with the vehicle control group, and the p53 protein expression levels were the same as noted with Western blotting. The immunoreactive DRGs colocalized with DAPI. To further characterize p53 and PARP1 in neuropathic DRG tissues and the sciatic nerve, the mRNA expression levels of p53 and PARP1 were determined by realtime PCR. Compared with the control group, the data revealed that p53 and PARP1 mRNA expression was increased in PTXtreated mice. In addition, duloxetine attenuated the PTXinduced increases in p53 and PARP1 mRNA expression levels in the DRG tissues (Fig. 3D) and sciatic nerve (Fig. 3E). The changes of mRNA expression were similar to that in primary rat DRG neurons (Supplemental Fig. 3).

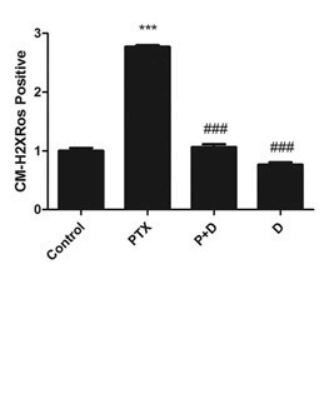

Duloxetine Blocked PTX-Induced Bcl2 Family in Neuropathic Mouse DRG Tissues and the Sciatic Nerve. The Bcl2 family of proteins plays a central role in the apoptosis process. The Bcl2 family includes Bcl2, Bax, Bcl2-associated agonist of cell death (Bad), and Bcl-2-like protein 1 (Bcl-xL) (Rahman et al., 2015; Zheng et al., 2016). Bax and Bad proteins promote apoptosis, whereas Bcl2 and Bcl-xL proteins inhibit apoptosis. In fact, the ratio of Bax to Bcl2 determines the sensitivity to cell death (Amin et al., 2014). Therefore, we employed Western blotting to determine whether the Bcl2 family was involved in cell apoptosis caused by PTX. PTX treatment increased Bax expression and markedly decreased the expression of the proapoptotic protein Bcl2 in DRG tissues and the sciatic nerve, as shown in Fig. 4, A and B. However, pretreatment with duloxetine effectively balanced this change; these data reveal that the Bcl2 family is involved in PTX-induced neuropathic pain, and duloxetine can attenuate their upregulation in DRGs. Then, we examined gene levels in the DRG and the sciatic nerve. The results suggested that duloxetine markedly regulated the mRNA expression of Bax/Bcl2 in the DRG and the sciatic nerve (Fig. 4, C and D), indicating that duloxetine has remarkable neuroprotective effects through apoptosis resistance.

Effect of p53 Inhibitor on Neurotoxicity and Cell Apoptosis Induced by PTX in Primary DRG Neurons. One of the most significant functions of p53 is inducing cell apoptosis. We have demonstrated that PIPN can be reduced by inhibiting p53. Pifithrin- $\alpha$, one of the most commonly used inhibitors of p53, has been reported to have efficacy in stroke 
A

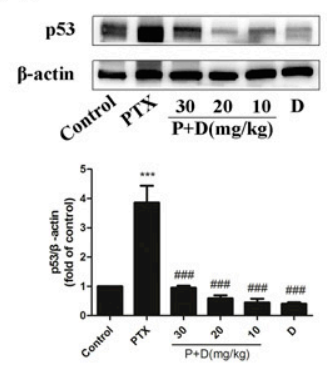

B
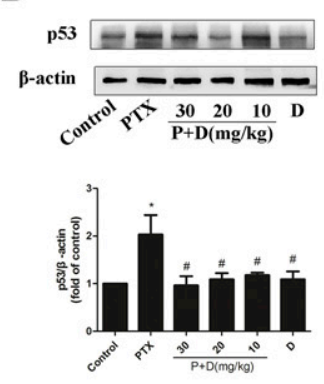

active PARP1

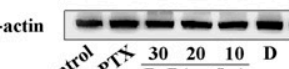

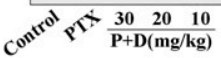
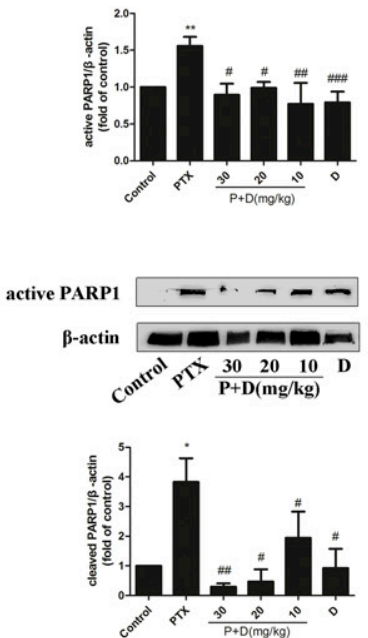

C

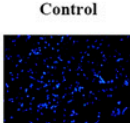

p53

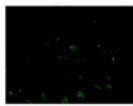

$\therefore$
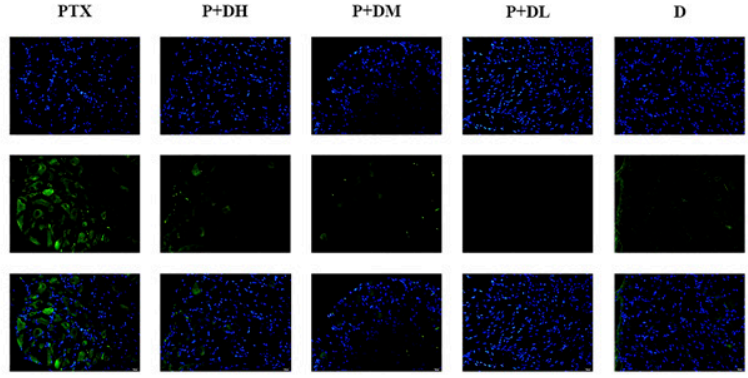

D
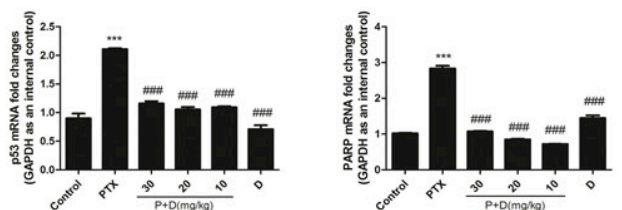

$\mathbf{E}$
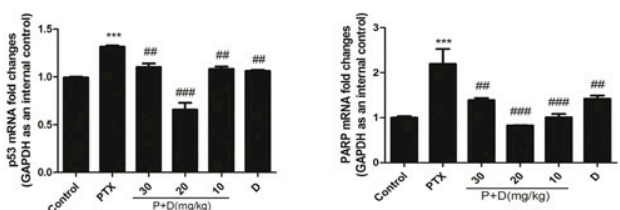

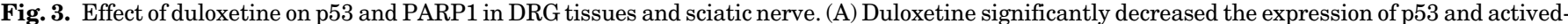

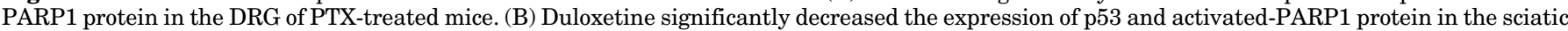

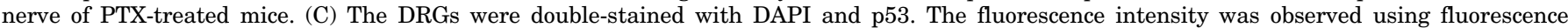

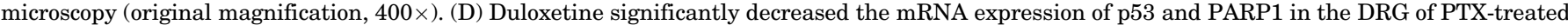

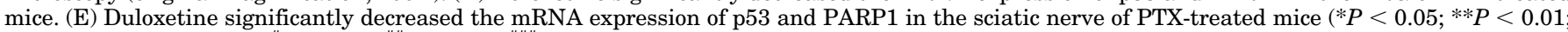
*** $P<0.001$ vs. control; ${ }^{\#} P<0.05$; ${ }^{\# \# ~} P<0.01$; ${ }^{\# \# ~} P<0.001$ vs. PTX, $\left.n=5\right)$. D, duloxetine; H, high; L, low; M, medium; P, paclitaxel.

models, seizures, and parkinson's disease (PD) models (Duan et al., 2002; Culmsee et al., 2003; Engel et al., 2010). Hence, we used the CCK- 8 assay to evaluate pft- $\alpha$-induced neuroprotection. As shown in Fig. 5A, 300 nM PTX caused approximately $40 \%$ neurotoxicity in DRG cells, and varying concentrations of pft- $\alpha$ (4.63-37 $\mu \mathrm{M})$ protected against PTX-induced neurotoxicity. Moreover, $18.5 \mu \mathrm{M}$ pft- $\alpha$ could better alleviate the neurotoxicity caused by PTX. To examine whether pft- $\alpha$ had an effect on the antitumour activity of PTX, we identified that 300 nM PTX killed at least $50 \%$ of PA-1 cancer cells, achieving a half-lethal dose,
A

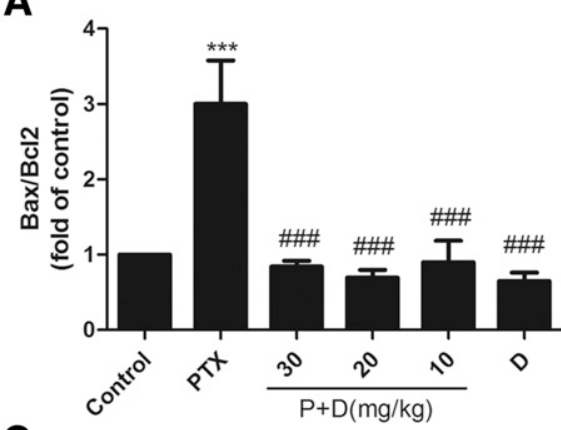

C

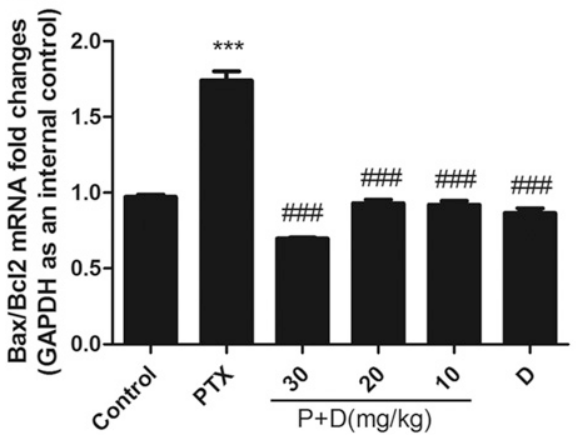

B
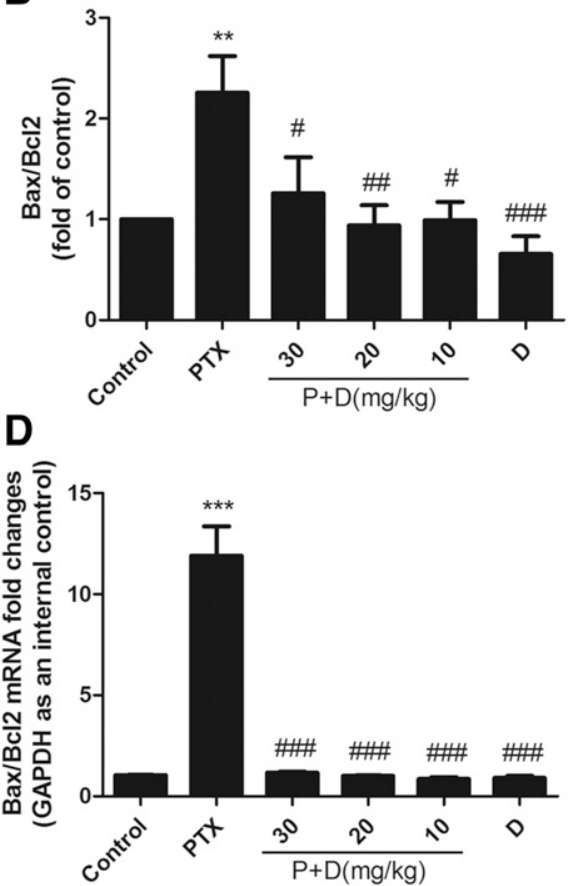

Fig. 4. Effect of duloxetine on Bax and Bcl2 in DRG tissues and the sciatic nerve. (A) Duloxetine significantly decreased the expression of $\mathrm{Bax} / \mathrm{Bcl} 2$ protein in the DRG of PTX-treated mice. (B) Duloxetine significantly decreased the expression of $\mathrm{Bax} / \mathrm{Bcl} 2$ protein in the sciatic nerve of PTX-treated mice. (C) Duloxetine significantly decreased the mRNA expression of $\mathrm{Bax} / \mathrm{Bcl} 2$ in the DRG of PTX-treated mice. (D) Duloxetine significantly decreased the mRNA expression of $\mathrm{Bax} / \mathrm{Bcl} 2$ in the sciatic nerve of PTX-treated mice $(* * P<0.01 ; * * * P<0.001$ vs. Control; ${ }^{\#} P<0.05$; ${ }^{\# \#} P<0.01$; ${ }^{\# \# \# ~} P<0.001$ vs. PTX, $n=5$ ). D, duloxetine; P, paclitaxel. 
whereas pretreatment of pft- $\alpha$ with various concentrations enhanced the capacity of PTX to kill PA-1 cancer cells (Fig. 5B). To determine whether inhibiting p53 could protect peripheral nerves by decreasing PTX-induced cell apoptosis, a flow cytometric analysis experiment was performed. We discovered that PTX treatment in DRG cells caused apoptosis after 24 hours, and the proportion of apoptotic cells increased significantly (30.57\%); however, apoptosis decreased markedly after treatment of $18.5 \mu \mathrm{M} \mathrm{pft}-\alpha(21.41 \%)$, indicating that pft- $\alpha$ affects PTX-induced apoptosis, as shown in Fig. 5C.

Duloxetine Attenuated PTX-Induced Cell Apoptosis via Inhibiting p53. Apoptosis plays a significant role in maintaining various cellular functions (Sharafi and Rahimi, 2012; Hassan et al., 2014). p53 is a cell cycle checkpoint protein, which is in response to DNA damage via mediating cell cycle stagnation or apoptosis, thereby contributing to the maintenance of genetic stability (Guan et al., 2008; Renaud et al., 2014). Because of the importance of p53 in the cell cycle, we investigated the effects of p53 siRNA on cell viability and Bcl2 family expression. As expected, when siRNA was used to reduce the level of p53, p53 siRNA strongly attenuated the PTX-induced decrease in cell viability, and cells were resistant to PTX toxicity (Fig. 6, A and B). At the same time, duloxetine provided the same neuroprotection. This result indicated that lowering p53 levels may be the main mechanism by which duloxetine participates in neuroprotection. On the other hand,
Western blotting showed that p53 siRNA treatment decreased cell apoptosis by decreasing the expression of $\mathrm{Bax} / \mathrm{Bcl} 2$ (Fig. 6C). Activation of p53 during DNA damage has been reported to activate downstream signaling to regulate apoptosis in cells, like the Bcl2 family. Taken together, the above experimental results obviously demonstrated that duloxetine suppressed PTX-induced cytotoxicity and apoptosis by inhibiting p53 and the downstream Bcl2 family.

\section{Discussion}

CIPN is the main dose-limiting toxicity caused by various chemotherapeutic agents. PTX is a chemotherapeutic drug, and it has been widely used in various solid tumors. However, peripheral neuropathic pain caused by PTX leads to loss of body function, a significant decline in quality of life, and even a delay in treatment. The peripheral neurotoxicity caused by PTX is rarely disabling, but it often lasts for several months to years after stopping the drug, causing inconvenience and impacting the patient's quality of life (Kiya et al., 2011). PTXinduced peripheral neurotoxicity usually occurs within 24-72 hours of administration, which is dose-accumulating with an incidence of 59\%-78\% (Wilkes, 2007).

With the proposal of the mechanism of PIPN, some prevention and treatment methods have emerged accordingly. Although there are many clinical trials on the treatment of
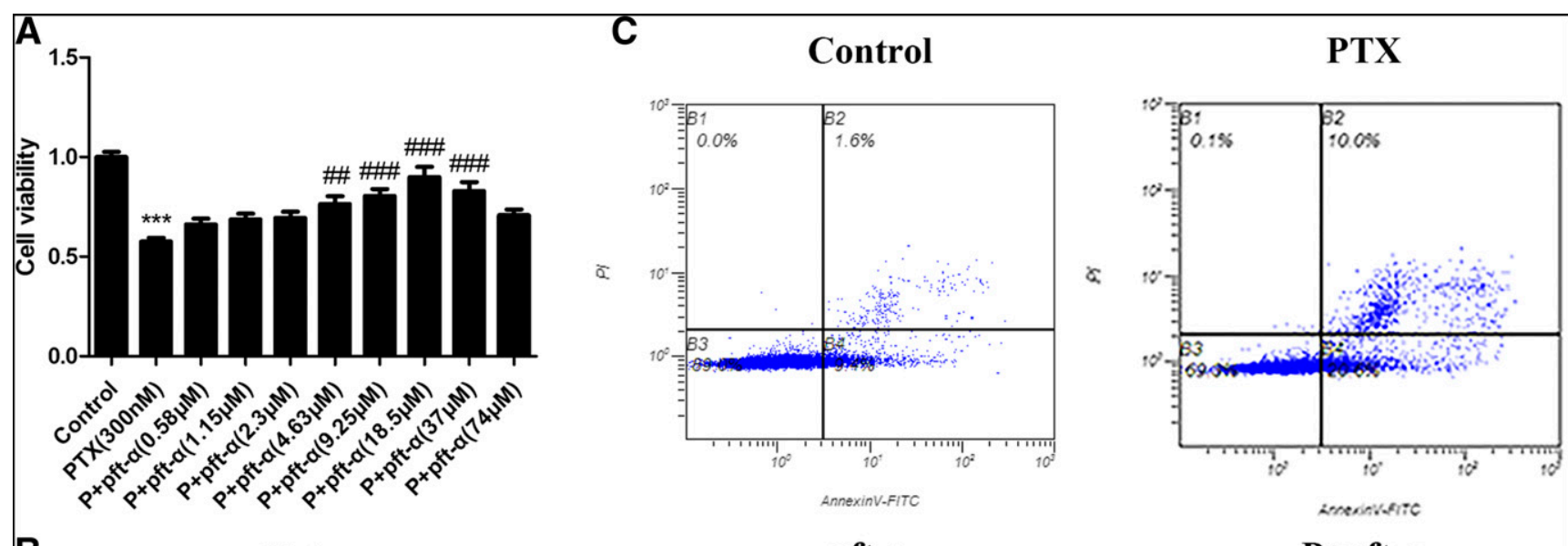

B

PA-1
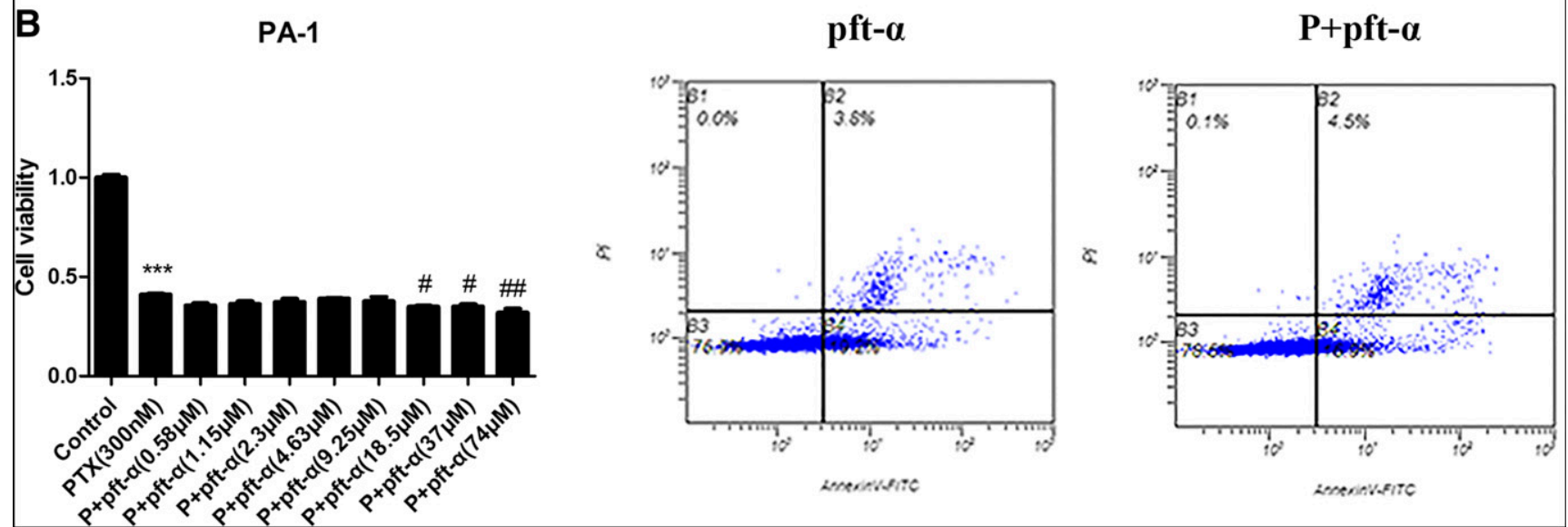

Fig. 5. Effect of pft- $\alpha$ on neurotoxicity and cell apoptosis caused by PTX in primary DRG neurons. (A) Primary rat DRG neurons were grown for 24 hours and then treated with PTX ( $300 \mathrm{nM}$ ) and/or various concentrations of pft- $\alpha$ for another 24 hours. (B) When PA-1 cancer cells were grown for 24 hours, various concentrations of pft- $\alpha$ together with PTX (300 nM) showed slight changes in cell viability compared with treatments with PTX alone. (C) After DRG cells were cultured for 24 hours, they were then exposed to PTX ( $300 \mathrm{nM})$ with or without pft- $\alpha(18.5 \mu \mathrm{M})$ for another 24 hours. Cells were doublestained with Annexin V-FITC/PI (***P $<0.001$ vs. control; ${ }^{\#} P<0.05 ;{ }^{\# \#} P<0.01$; ${ }^{\# \#} P<0.001$ vs. PTX, $n=6$ ). P, paclitaxel. 
PIPN, there is no unified standard in clinical treatment. To date, there have been 42 randomized controlled clinical trials of drug prophylaxis against CIPN, but none of these trials has provided any convincing evidence, and the specific mechanism is unclear. The American Society of Clinical Oncology guidelines note that duloxetine is the only drug available to treat CIPN. There is a lack of high-quality, consistent data to support the use of drugs other than duloxetine. Moreover, duloxetine is considered to be related to the regulation of neuropathic pain.

Based on a previous report, we used DRG neurons herein extracted from primary rats (Meng et al., 2019). Our results showed that PTX caused an increase in mitochondrial oxidative stress levels in the DRG. The intervention of duloxetine inhibits peroxidation and protects cells from nerve damage, partially alleviating CIPN. Many experimental and basic research studies conducted by scholars on PIPN have found that PIPN is in connection with structural damage of mitochondria and peripheral nerves in the DRG (Zheng et al., 2011). Damage to intracellular mitochondria causes oxidative stress, inflammation, and proapoptotic signaling (Mecocci et al., 1994). Oxidative stress is an important and common way to prevent or reverse CIPN. When cells have weak antioxidant defense ability, they are particularly susceptible to oxidative damage induced by chemotherapy (Low et al., 1997). Duggett et al. (2016) found that during the early development of neuropathic pain caused by PTX, reactive oxygen species (ROS) levels increased in tissue, producing oxidative stress.

Neuropathic pain is evoked by damage or disturbances that affect the somatosensory system, involving the activation of the pain and analgesia pathway (Jensen et al., 2011; Lisi et al., 2015). Duloxetine is an important drug. The behavioral evaluation of mice indicated that duloxetine can effectively improve PTX-induced thermal pain and mechanical allodynia in mice for the treatment of abnormal reactions to innocuous stimuli (hyperpathic pain) or noxious stimuli (hyperalgesia) (Bellingham and Peng, 2010). In our experiments, we had access to a mouse PIPN model with reference to the modeling method (Melli et al., 2006; Zhu et al., 2013; Krukowski et al., 2015). The results showed that PTX injected intraperitoneally every other day caused hyperalgesia and thermal hyperalgesia in mice, but not sensitivity to cold pain stimulation. PTX also had little effect on body weight. It was found that duloxetine can effectively improve PTX-induced thermal and mechanical allodynia in mice. It has been reported in previous
A

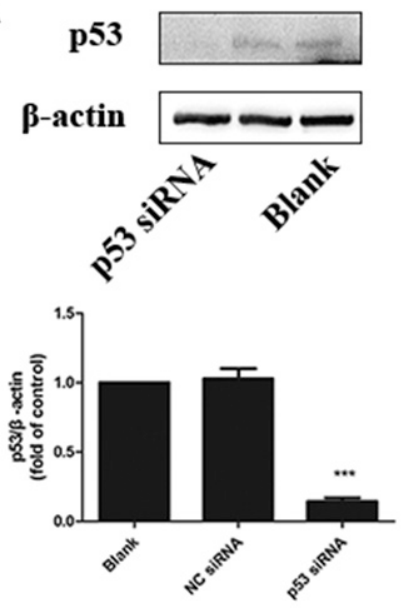

C

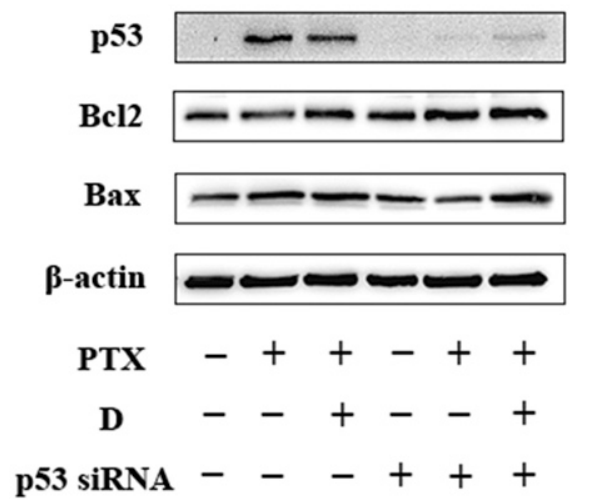

B
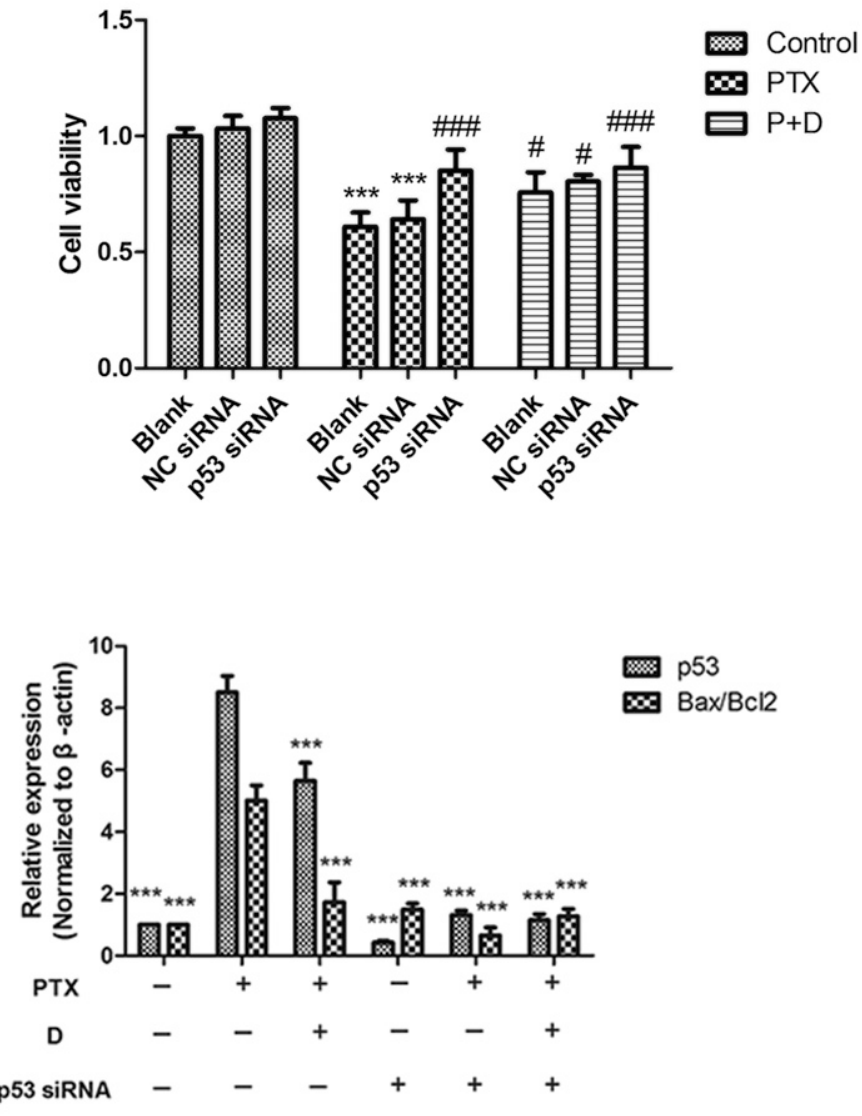

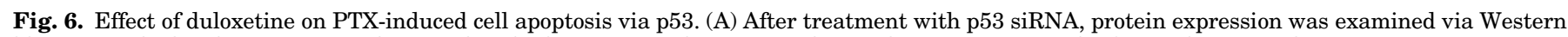

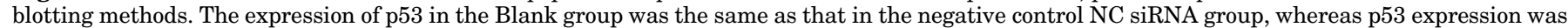

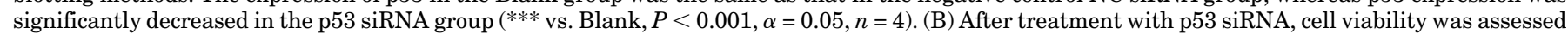

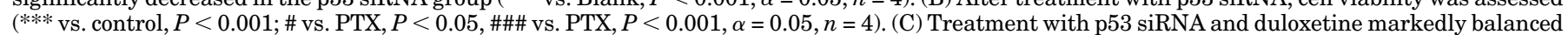
the protein expression of Bax/Bcl2 in PTX-treated DRG cells (*** vs. PTX, $P<0.001, \alpha=0.05, n=4$ ). D, duloxetine; P, paclitaxel. 
studies that chemotherapy-induced neuropathic pain is related to enhancive oxidative stress (Di Cesare Mannelli et al., 2012). Inhibition of reactive oxygen species (ROS) accumulation is a significant mechanism to prevent nerve cell damage. Our study suggested that duloxetine inhibited oxidative stress, and pretreatment of duloxetine prevented pain hypersensitivity, indicating that duloxetine improves neuropathic pain through reducing oxidative stress.

Apoptosis is a cascade of activating cell death after stimulation by varieties of death-inducing signaling complex and plays a significant role in the maintenance of multiplex cellular functions. p53 and PARP1 are involved in cellular regulation as apoptosis-related proteins. The present research showed that the nuclear translocation of p53 is increased when tumor cells are treated with microtubule-targeted drugs, including PTX (Giannakakou et al., 2000; Carney et al., 2012). It has been reported that Bcl2 was downregulated, whereas p53 and Bax were upregulated, when cells were treated with PTX, suggesting that apoptosis initiates through a p53-dependent pathway (Thomas et al., 2015). PARP is a DNA-sensitive enzyme that can identify singlestranded DNA strand breaks and initiate repair through the base excision repair (BER) pathway. Besides, it has been shown that activation of PARP is able to evoke a variety of apoptotic signaling events (Schreiber et al., 2006). Our experimental results proved that PTX-induced apoptosis was connected with p53 and an imbalance in the expression of the Bcl 2 family members; nevertheless, pretreatment with duloxetine significantly inhibited the upregulation of p53 and Bax and the downregulation of Bcl2. In addition, cleaved PARP can lead to apoptosis. The quantitative expression of PARP1 in protein and gene levels further confirmed the function of PARP1 in PTX-induced apoptosis. However, as indicated by PARP cleavage, pretreatment with duloxetine markedly blocked the process of apoptosis. Additionally, pft- $\alpha$ provided a neuroprotective effect, which revealed that inhibiting p53 can reduce PTX-induced apoptosis and achieve neuroprotection. This finding also provides a practical basis for the use of $\mathrm{pft}-\alpha$ to improve CIPN. Moreover, our further studies revealed that p53 siRNA had a neuroprotective effect on cell neurons and downregulated the expression levels of Bax and Bcl2, thereby partially inhibiting cytotoxicity and cell apoptosis induced by PTX. These above results demonstrated that duloxetine has the possibility to improve PIPN through inhibiting cell apoptosis mediated by p53 through its downstream signals, the Bcl2 family and PARP1.

In summary, our study suggested that duloxetine exerts an antihyperalgesic effect on mechanical and heat hyperalgesia in mice and alleviates PTX-induced cytotoxicity and apoptosis by suppressing oxidative stress and activating p53 and the Bcl2 family and PARP1. Therefore, duloxetine has potential as a new therapeutic agent targeting p53-related apoptotic pathways to ameliorate PTX-induced peripheral neuropathic pain and nerve injury and decrease adverse reaction of antitumour drugs.

\section{Authorship Contributions}

Participated in research design: Lu, P. Zhang, Q. Zhang, Yang, Zhu.

Conducted experiments: Lu, P. Zhang, Q. Zhang, Qian, Suo, Tao.

Contributed new reagents or analytic tools: Q. Zhang, Zhu.

Performed data analysis: Lu, P. Zhang, Q. Zhang, Yang, Qian, Suo.
Wrote or contributed to the writing of the manuscript: Lu, P. Zhang, Q. Zhang, Zhu.

\section{References}

Amin B, Hajhashemi V, Abnous K, and Hosseinzadeh H (2014) Ceftriaxone, a betalactam antibiotic, modulates apoptosis pathways and oxidative stress in a rat model of neuropathic pain. BioMed Res Int 2014.937568.

Brandolini L, Castelli V, Aramini A, Giorgio C, Bianchini G, Russo R, De Caro C, d'Angelo M, Catanesi M, Benedetti E, et al. (2019) DF2726A, a new IL-8 signalling inhibitor, is able to counteract chemotherapy-induced neuropathic pain. Sci Rep $\mathbf{9}$ : 11729.

Bellingham GA and Peng PW (2010) Duloxetine: a review of its pharmacology and use in chronic pain management. Reg Anesth Pain Med 35:294-303.

Carney BK, Caruso Silva V, and Cassimeris L (2012) The microtubule cytoskeleton is required for a G2 cell cycle delay in cancer cells lacking stathmin and p53. Cytoskeleton (Hoboken) 69:278-289.

Culmsee C and Landshamer S (2006) Molecular insights into mechanisms of the cell death program: role in the progression of neurodegenerative disorders. Curr Alzheimer Res 3:269-283.

Culmsee C and Mattson MP (2005) p53 in neuronal apoptosis. Biochem Biophys Res Commun 331:761-777.

Culmsee C, Siewe J, Junker V, Retiounskaia M, Schwarz S, Camandola S, El-Metainy S, Behnke H, Mattson MP, and Krieglstein J (2003) Reciprocal inhibition of p53 and nuclear factor-kappaB transcriptional activities determines cell survival or death in neurons. $J$ Neurosci 23:8586-8595.

Cata JP, Weng HR, Lee BN, Reuben JM, and Dougherty PM (2006) Clinical and experimental findings in humans and animals with chemotherapy-induced peripheral neuropathy. Minerva Anestesiol 72:151-169.

Di Cesare Mannelli L, Zanardelli M, Failli P, and Ghelardini C (2012) Oxaliplatininduced neuropathy: oxidative stress as pathological mechanism. Protective effect of silibinin. J Pain 13:276-284.

Dougherty PM, Cata JP, Cordella JV, Burton A, and Weng HR (2004) Taxol-induced sensory disturbance is characterized by preferential impairment of myelinated fiber function in cancer patients. Pain 109:132-142.

Duan W, Zhu X, Ladenheim B, Yu QS, Guo Z, Oyler J, Cutler RG, Cadet JL, Greig $\mathrm{NH}$, and Mattson MP (2002) p53 inhibitors preserve dopamine neurons and motor function in experimental parkinsonism. Ann Neurol 52:597-606.

Duggett NA, Griffiths LA, McKenna OE, de Santis V, Yongsanguanchai N, Mokori EB, and Flatters SJL (2016) Oxidative stress in the development, maintenance and resolution of paclitaxel-induced painful neuropathy. Neuroscience 333:13-26.

Engel T, Murphy BM, Hatazaki S, Jimenez-Mateos EM, Concannon CG, Woods I, Prehn JHM, and Henshall DC (2010) Reduced hippocampal damage and epileptic seizures after status epilepticus in mice lacking proapoptotic Puma. FASEB J 24: 853-861.

Eum S, Choi HD, Chang MJ, Choi HC, Ko YJ, Ahn JS, Shin WG, and Lee JY (2013) Protective effects of vitamin E on chemotherapy-induced peripheral neuropathy: a meta-analysis of randomized controlled trials. Int $J$ Vitam Nutr Res 83:101-111.

Finnerup NB, Attal N, Haroutounian S, McNicol E, Baron R, Dworkin RH, Gilron I, Haanpää M, Hansson P, Jensen TS, et al. (2015) Pharmacotherapy for neuropathic pain in adults: a systematic review and meta-analysis. Lancet Neurol 14:162-173.

Giannakakou P, Sackett DL, Ward Y, Webster KR, Blagosklonny MV, and Fojo T (2000) p53 is associated with cellular microtubules and is transported to the nucleus by dynein. Nat Cell Biol 2:709-717.

Gihyun L and Sun K (2016) Therapeutic effects of phytochemicals and medicinal herbs on chemotherapy-induced peripheral neuropathy. Molecules 21:E1252

Guan L, Huang F, Li Z, Han B, Jiang Q, Ren Y, Yang Y, and Xu C (2008) P53 transcription-independent activity mediates selenite-induced acute promyelocytic leukemia NB4 cell apoptosis. BMB Rep 41:745-750.

Hagiwara H and Sunada Y (2004) Mechanism of taxane neurotoxicity. Breast Cancer 11:82-85.

Haince JF, Rouleau M, Hendzel MJ, Masson JY, and Poirier GG (2005) Targeting poly(ADP-ribosyl)ation: a promising approach in cancer therapy. Trends Mol Med 11:456-463.

Hassan M, Watari H, AbuAlmaaty A, Ohba Y, and Sakuragi N (2014) Apoptosis and molecular targeting therapy in cancer. BioMed Res Int 2014:150845.

Jensen TS, Baron R, Haanpää M, Kalso E, Loeser JD, Rice ASC, and Treede RD (2011) A new definition of neuropathic pain. Pain 152:2204-2205.

Jensen TS and Finnerup NB (2014) Allodynia and hyperalgesia in neuropathic pain: clinical manifestations and mechanisms. Lancet Neurol 13:924-935.

Kiya T, Kawamata T, Namiki A, and Yamakage M (2011) Role of satellite cell-derived L-serine in the dorsal root ganglion in paclitaxel-induced painful peripheral neuropathy. Neuroscience 174:190-199.

Krukowski K, Nijboer CH, Huo X, Kavelaars A, and Heijnen CJ (2015) Prevention of chemotherapy-induced peripheral neuropathy by the small-molecule inhibitor pifithrin- $\mu$. Pain 156:2184-2192.

Kuzhandaivel A, Nistri A, and Mladinic M (2010) Kainate-mediated excitotoxicity induces neuronal death in the rat spinal cord in vitro via a PARP-1 dependent cell death pathway (Parthanatos). Cell Mol Neurobiol 30:1001-1012.

Langelier MF, Servent KM, Rogers EE, and Pascal JM (2008) A third zinc-binding domain of human poly(ADP-ribose) polymerase-1 coordinates DNA-dependent enzyme activation. J Biol Chem 283:4105-4114.

Lisi L, Aceto P, Navarra P, and Dello Russo C (2015) mTOR kinase: a possible pharmacological target in the management of chronic pain. BioMed Res Int 2015: 394257.

Low PA, Nickander KK, and Tritschler HJ (1997) The roles of oxidative stress and antioxidant treatment in experimental diabetic neuropathy. Diabetes 46 (Suppl 2): S38-S42. 
McNeish IA, Bell SJ, and Lemoine NR (2004) Gene therapy progress and prospects: cancer gene therapy using tumour suppressor genes. Gene Ther 11 (6):497-503, doi: 10.1038/sj.gt.3302238 14762396 .

Mecocci P, MacGarvey U, and Beal MF (1994) Oxidative damage to mitochondrial DNA is increased in Alzheimer's disease. Ann Neurol 36:747-751.

Melli G, Jack C, Lambrinos GL, Ringkamp M, and Höke A (2006) Erythropoietin protects sensory axons against paclitaxel-induced distal degeneration. Neurobiol Dis 24:525-530.

Meng J, Zhang Q, Yang C, Xiao L, Xue Z, and Zhu J (2019) Duloxetine, a balanced serotonin-norepinephrine reuptake inhibitor, improves painful chemotherapyinduced peripheral neuropathy by inhibiting activation of p38 MAPK and NFкB. Front Pharmacol 10:365.

Miyazaki R and Yamamoto T (2012) The efficacy of morphine, pregabalin, gabapentin, and duloxetine on mechanical allodynia is different from that on neuroma pain in the rat neuropathic pain model. Anesth Analg 115:182-188.

Neitemeier S, Ganjam GK, Diemert S, and Culmsee C (2014) Pifithrin- $\alpha$ provides neuroprotective effects at the level of mitochondria independently of p53 inhibition. Apoptosis 19:1665-1677.

Plesnila N, von Baumgarten L, Retiounskaia M, Engel D, Ardeshiri A, Zimmermann R, Hoffmann F, Landshamer S, Wagner E, and Culmsee C (2007) Delayed neurona death after brain trauma involves p53-dependent inhibition of NF-kappaB transcriptional activity. Cell Death Differ 14:1529-1541.

Renaud J, Bournival J, Zottig X, and Martinoli MG (2014) Resveratrol protects DAergic PC12 cells from high glucose-induced oxidative stress and apoptosis: effect on p53 and GRP75 localization. Neurotox Res 25:110-123.

Rahman MA, Shirai M, Aziz MA, Ushirokita R, Kubota S, Suzuki H, and Azuma Y (2015) An epistatic effect of apaf-1 and caspase-9 on chlamydial infection. Apoptosis 20:1271-1280.

Schreiber V, Dantzer F, Ame JC, and de Murcia G (2006) Poly(ADP-ribose): novel functions for an old molecule. Nat Rev Mol Cell Biol 7:517-528.

Sharafi H and Rahimi R (2012) The effect of resistance exercise on p53, caspase-9, and caspase- 3 in trained and untrained men. J Strength Cond Res 26:1142-1148.

Shidahara Y, Ogawa S, Nakamura M, Nemoto S, Awaga Y, Takashima M, Hama A Matsuda A, and Takamatsu H (2016) Pharmacological comparison of a nonhuman primate and a rat model of oxaliplatin-induced neuropathic cold hypersensitivity. Pharmacol Res Perspect 4:e0216.

Takenaka M, Iida H, Matsumoto S, Yamaguchi S, Yoshimura N, and Miyamoto M (2013) Successful treatment by adding duloxetine to pregabalin for peripheral neuropathy induced by paclitaxel. Am J Hosp Palliat Care 30:734-736.

Thakur B and Ray P (2016) p53 Loses grip on PIK3CA expression leading to enhanced cell survival during platinum resistance. Mol Oncol 10:1283-1295.

Thomas GE, Sreeja JS, Gireesh KK, Gupta H, Manna TK, and Manna TK (2015) +TIP EB1 downregulates paclitaxel-induced proliferation inhibition and apoptosis in breast cancer cells through inhibition of paclitaxel binding on microtubules. Int J Oncol 46:133-146.
Toyama S, Shimoyama N, and Shimoyama M (2017) The analgesic effect of orexin-A in a murine model of chemotherapy-induced neuropathic pain. Neuropeptides $\mathbf{6 1}$ 95-100.

Vousden KH and Prives C (2009) Blinded by the light: the growing complexity of p53. Cell 137:413-431.

Wang K, Fu XY, Fu XT, Hou YJ, Fang J, Zhang S, Yang MF, Li DW, Mao LL, Sun JY, et al. (2016) DSePA antagonizes high glucose-induced neurotoxicity: evidences for DNA damage-mediated p53 phosphorylation and MAPKs and AKT pathways. Mol Neurobiol 53:4363-4374.

Wang Y, Zhou L, Xiao M, Sun ZL, and Zhang CY (2017) Nanomedicine-based paclitaxel induced apoptotic signaling pathways in A562 leukemia cancer cells. Colloids Surf B Biointerfaces 149:16-22.

Wilkes G (2007) Peripheral neuropathy related to chemotherapy. Semin Oncol Nurs 23:162-173.

Wolf S, Barton D, Kottschade L, Grothey A, and Loprinzi C (2008) Chemotherapyinduced peripheral neuropathy: prevention and treatment strategies. Eur J Cancer 44:1507-1515

Xiang H, Hochman DW, Saya H, Fujiwara T, Schwartzkroin PA, and Morrison RS (1996) Evidence for p53-mediated modulation of neuronal viability. J Neurosci 16: 6753-6765.

Xu WL, Tayerjiang JL, Zhao XB, Wang H, Wang Q, and Yuan H (2015) Study of optimal scheme of spinal image-guided radiotherapy based on expression of caspase-3 in spinal cord neurons by orthogonal design. Genet Mol Res 14 $3223-3233$.

Yang YH, Lin JK, Chen WS, Lin TC, Yang SH, Jiang JK, Chang SC, Lan YT, Lin CC, Yen CC, et al. (2012) Duloxetine improves oxaliplatin-induced neuropathy in patients with colorectal cancer: an open-label pilot study. Support Care Cancer 20:1491-1497.

Yin X, Yin Y, Cao FL, Chen YF, Peng Y, Hou WG, Sun SK, and Luo ZJ (2012) Tanshinone IIA attenuates the inflammatory response and apoptosis after traumatic injury of the spinal cord in adult rats. PLoS One 7:e38381.

Zheng JH, Viacava Follis A, Kriwacki RW, and Moldoveanu T (2016) Discoveries and controversies in BCL-2 protein-mediated apoptosis. FEBS J 283:2690-2700.

Zheng H, Xiao WH, and Bennett GJ (2011) Functional deficits in peripheral nerve mitochondria in rats with paclitaxel- and oxaliplatin-evoked painful peripheral neuropathy. Exp Neurol 232:154-161

Zhu J, Chen W, Mi R, Zhou C, Reed N, and Höke A (2013) Ethoxyquin prevents chemotherapy-induced neurotoxicity via Hsp90 modulation. Ann Neurol 74: 893-904.

Address correspondence to: Jing Zhu, Jiangsu Key Laboratory for Pharmacology and Safety Evaluation of Chinese Materia Medica, Department of Pharmacy, Nanjing University of Chinese Medicine, Nanjing 210023, China. E-mail: 830640@njucm.edu.cn 